Research Article

\title{
Damage Strengthening Constitutive Model of Cemented Paste Backfill
}

\author{
Kangli Cheng $\mathbb{D}^{1},{ }^{1}$ Bingbing Tu $\mathbb{D}^{\mathbb{D}},{ }^{2}$ Lang Liu $\mathbb{D}^{1},{ }^{1,3}$ Bo Zhang $\mathbb{D}^{1},{ }^{1}$ and Huafu Qiu $\mathbb{D}^{1}$ \\ ${ }^{1}$ Energy School, Xi'an University of Science and Technology, Xi'an 710054, China \\ ${ }^{2}$ College of Science, Xi'an University of Science and Technology, Xi'an 710054, China \\ ${ }^{3}$ Key Laboratory of Western Mines and Hazards Prevention, Ministry of Education of China, Xi'an 710054, China \\ Correspondence should be addressed to Kangli Cheng; xustckl@163.com, Bingbing Tu; tubingbing9@xust.edu.cn, Lang Liu; \\ liulang@xust.edu.cn, and Bo Zhang; bozhang@xust.edu.cn
}

Received 31 January 2021; Revised 3 March 2021; Accepted 7 April 2021; Published 30 April 2021

Academic Editor: Qianqian Wang

Copyright (c) 2021 Kangli Cheng et al. This is an open access article distributed under the Creative Commons Attribution License, which permits unrestricted use, distribution, and reproduction in any medium, provided the original work is properly cited.

\begin{abstract}
In order to consider the influence of mesoscopic characteristics of materials on the constitutive model of cemented paste backfill $(\mathrm{CPB})$, the uniaxial compression variables and the damage constitutive model, considering the influence of porosity and pore size of filling materials, were derived based on the strain equivalence principle and Weibull probability distribution function. The nuclear magnetic resonance (NMR) tests and unconfined compression strength (UCS) tests were carried out on 8 groups of CPB specimens with different slurry concentrations and cement-tailings ratios. Then, the expression of damage strengthening coefficient is determined, and the stress-strain curves measured by the theoretical model were compared with the experimental ones. The results show that the uniaxial compression constitutive model proposed is in good agreement with UCS test results and can effectively describe the damage evolution law and the development process of stress-strain curve of CPB under uniaxial compression. The 28-day compressive strength of $\mathrm{CPB}$ can reach $8 \mathrm{MPa}$, the residual strength is about $1 \sim 2 \mathrm{MPa}$, the elastic modulus is about 200 2000 MPa, and the porosity is about 3 5\%. The CPB with slurry concentration of $74 \%$ and $76 \%$ and cement-tailings ratio of $1: 4$ and $1: 6$ is more reasonable, and the relevant mechanical parameters are more stable.
\end{abstract}

\section{Introduction}

In recent years, the global industrialization process is accelerating, the demand for mineral resources is increasing, the mining rate is increasing, and the tailings accumulation is increasing [1]. The storage of tailings wastes not only wastes land resources but also causes increasingly serious environmental problems (water pollution, air pollution, surface collapse, vegetation destruction, etc.) [2, 3]. Backfill mining technique is widely used in underground mine engineering because of its advantages of saving tailings waste storage place, reducing environmental pollution, effectively controlling ground pressure in goaf, ensuring safe operation, and so on [4-6]. Cemented paste backfill (CPB) is a kind of multiphase material formed by mixing a certain proportion of tailings and water with cement as the main cementation material and through mixing, vibrating, curing, and other processes. It has the advantages of no pollution, low energy consumption, and good roof connection performance when used in underground mine filling $[7,8]$. Whether the strength of $\mathrm{CPB}$ meets the requirements is an important basis for the effective implementation of backfill mining technology $[9,10]$.

At present, scholars have systematically studied the mechanical properties of $\mathrm{CPB}$ and achieved remarkable results. Hou et al. [11] studied the damage characteristics and energy dissipation analysis of $\mathrm{CPB}$ with different curing ages under uniaxial compression. Zhao et al. [12] explored the destruction process and mechanical properties of $\mathrm{CPB}$ with different slurry concentrations through uniaxial compression acoustic emission test. Yi et al. [13] discussed the damage and destruction evolution process of $\mathrm{CPB}$ with different waste rock contents through uniaxial compression real-time CT scanning mechanical test. In order to obtain the 
constitutive model of filling material, Liu et al. [14] and Zhao et al. [15] established the damage constitutive model of CPB by introducing the effective damage rate parameter on the basis of Weibull distribution law. Wang et al. [16] set up the damage evolution and constitutive model of CPB by using the damage mechanics theory and considering the delamination effect and studied the mechanical properties of different layered CPB. Cui and Fall [17] built an elasticplastic evolution model to research the important role of hydration of gelling agent on the mechanical behavior and property evolution of CPB. Wang et al. [18] established the paste damage constitutive model at different initial temperatures and proposed the paste temperature-time coupling damage constitutive model through parameter regression of the constitutive model. Cui and Fall [19] set up a thermohydro-mechanical chemical coupling model for CPB and studied the mechanical characteristics under multiphysical environment. Liu et al. [20] built the constitutive equation based on damage mechanics through the mechanical test of $\mathrm{CPB}$ with different cement-tailings ratios and discussed the reasonable matching between $\mathrm{CPB}$ and rock.

Wittmann et al. [21] believed that due to the differences in representational scales and research methods, according to the internal structure characteristics of the cemented tailings backfill, the mechanical properties of the backfill can be generally described in three different scales (macroscale, mesoscale, and microscale). In macroscale, the cemented tailings backfill is a single homogeneous body formed by mixing cement, tailings, and water cementing. Studies at this scale cannot reveal the relationship between the internal structure, composition, and mechanical properties of the backfill [22]. In mesoscale, the cemented tailings backfill can be regarded as a multiphase composite material composed of tailings, gel matrix, and initial defects (pores and cavities). Existing researches on the constitutive model of CPB mostly consider the influence of external factors such as material composition and ratio, external environment, and loading mode. In other words, the mechanical properties of backfill were studied from the macroscopic scale, while the influence of microscopic properties such as pore defects in the material on the mechanical effects of backfill was ignored. During the process of hydration and hardening, the intercalated pores of hydrated calcium silicate (C-S-H) gel, capillary pores formed by evaporation and loss of water not involved in hydration reaction, and bubble pores formed by residual air during slurry mixing formed in CPB $[23,24]$. This makes the CTB have the properties of porous material, the pore distribution is complex, and the pore size spans the microcosmic and microscale. The formation, destruction, and expansion of initial pores will have a significant impact on the strength, stiffness, damage failure, and other basic mechanical parameters [25-28].

Considering the influence of mesoscopic pore characteristics of $\mathrm{CPB}$, a damage constitutive model based on damage strengthening coefficient is derived. Then, the effectiveness of the model is verified by combining nuclear magnetic resonance (NMR) test and unconfined compression strength (UCS) test, and the damage evolution law of $\mathrm{CPB}$ under uniaxial compression is analyzed, which provides a basis for understanding the basic mechanical properties of CPB.

\section{Damage Strengthening Coefficient}

Porosity and pore size are important parameters affecting the mechanical properties of CPB [29-31]. In this paper, the porosity and pore size of the CPB specimen are taken as the initial defect measurement index of the material, and the damage strengthening coefficient of the $\mathrm{CPB}$ is defined as

$$
\alpha=f(P, d),
$$

where $\alpha$ is the damage strengthening coefficient; $P$ is the porosity; and $d$ is the pore size.

Referring to the functional relationship between pore size and strength of concrete material [31], the relationship between damage strengthening coefficient of CPB and porosity and pore size is defined as

$$
\alpha=G d^{H}(1+P)^{k}+c,
$$

where $G, H$, and $c$ are the test parameter, which are related to the slurry concentration, cement-tailings ratio, tailings type, cement type, etc.

\section{Damage Constitutive Model}

3.1. Model Establishment. According to the principle of strain equivalence proposed by Professor Lemaitre [32], a famous French scholar, any stress-strain constitutive relation of damaged materials under uniaxial loading can be derived from the constitutive equation of nondestructive materials, as long as the nominal stress in the constitutive relation of nondestructive materials is replaced by the effective stress after damage. Assuming that the effective bearing area of the $\mathrm{CPB}$ specimen is $A$ in the nondestructive state and $A_{1}$ after loading damage, the nominal stress of the section under loading is as follows:

$$
\sigma=\frac{F}{A} .
$$

The effective stress $\sigma^{*}$ on the effective section is

$$
\sigma^{*}=\frac{F}{A_{1}} .
$$

The damage variable $D$ is defined as

$$
D=\frac{A-A_{1}}{A} .
$$

In combination with equations (3)-(5), it is obtained that

$$
\sigma^{*}=\frac{\sigma}{(1-D)} \text {. }
$$

Then,

$$
\sigma=(1-D) \sigma^{*} .
$$

From $\sigma^{*}=E \varepsilon$, the damage constitutive equation of $\mathrm{CPB}$ can be obtained as follows: 


$$
\sigma=E(1-D) \mathcal{\varepsilon}
$$

where $E$ is the elastic modulus of CPB.

Previous studies $[14,15]$ have shown that the mechanical properties of mesoscopic heterogeneity of quasibrittle materials obey a certain statistical law. According to the shape characteristics of stress-strain curve of CPB, the nominal damage variable $D_{0}$ is selected to obey the two-parameter Weibull distribution equation:

$$
D_{0}=1-\exp \left[-\left(\frac{\varepsilon}{a}\right)\right]^{m}
$$

where $\varepsilon$ is the strain; $m$ and $a$ are the coefficient related to the physical and mechanical properties of $\mathrm{CPB}$, and it is not negative.

At the initial stage of compression, the pores in the CPB are compacted. The existence of pore structure weakens the material properties of $\mathrm{CPB}$ and accelerates the damage rate. In this paper, the influence of pore structure on the damage degree of CPB specimen is characterized by the damage strengthening coefficient as shown in equation (2), and the damage variable $D$ is defined as

$$
D=\alpha D_{0} .
$$
obtain

By introducing equation (9) into equation (11), we

$$
D=\alpha\left(1-\exp \left[-\left(\frac{\varepsilon}{a}\right)\right]^{m}\right)
$$

By introducing equation (11) into equation (8), it is obtained that

$$
\sigma=E \varepsilon\left\{1-\alpha\left(1-\exp \left[-\left(\frac{\varepsilon}{a}\right)^{m}\right]\right)\right.
$$

The results are as follows:

$$
\sigma=(1-\alpha) E \varepsilon+\alpha E \varepsilon \exp \left[-\left(\frac{\varepsilon}{a}\right)^{m}\right] .
$$

Under the action of stress, the CPB specimens are gradually damaged, and the internal structure is destroyed. When the strain exceeds a certain limit and the external stress is at a low stress level again, the internal structural damage tends to be stable, but the specimen still has a certain residual strength. Based on this, the damage threshold $\gamma$ is introduced. When the strain is $\gamma$, the damage variable in the CPB reaches the maximum damage $D_{\gamma}$, and the corresponding stress is residual strength. Then, the two-stage damage variable and damage constitutive equation are defined:

$$
\begin{aligned}
& D=\left\{\begin{array}{l}
\alpha\left(1-\exp \left[-\left(\frac{\varepsilon}{a}\right)\right]^{m}\right), \quad(\varepsilon<\gamma), \\
D_{\gamma}, \quad(\varepsilon \geq \gamma)
\end{array}\right. \\
& \sigma= \begin{cases}(1-\alpha) E \varepsilon+\alpha E \varepsilon \exp \left[-\left(\frac{\varepsilon}{a}\right)^{m}\right], & (\varepsilon<\gamma) \\
\sigma_{\gamma}, \quad(\varepsilon \geq \gamma)\end{cases}
\end{aligned}
$$

3.2. Model Establishment. According to the damage constitutive equation of $\mathrm{CPB}$, the stress-strain curve of the whole process is obtained as shown in Figure 1. It can be seen from Figure 1 that the constitutive curve satisfies the following four boundary conditions:

(1) $\varepsilon=0, \sigma=0 ;(2) \varepsilon=0, \mathrm{~d} \sigma / \mathrm{d} \varepsilon=E ;(3) \sigma=\sigma_{\mathrm{pk}}, \varepsilon=\varepsilon_{\mathrm{pk}}$; (4) $\sigma=\sigma_{\mathrm{pk}}, \mathrm{d} \sigma / \mathrm{d} \varepsilon=0$, where $\sigma_{p k}, \varepsilon_{p k}$, and $E$ are the peak stress, peak load strain, and elastic modulus.

According to (1), (2), (3), and (4) of the stress-strain curve, the sum of two undetermined parameters in equation (14) can be determined. Among them, conditions (1) and (2) are naturally satisfied.

By introducing condition (3) into equation (13), it is obtained that

$$
\sigma_{p k}=(1-\alpha) E \varepsilon_{p k}+\alpha E \varepsilon_{p k} \exp \left[-\left(\frac{\varepsilon_{p k}}{a}\right)^{m}\right] .
$$

Then,

$$
\frac{\sigma_{p k}}{E \varepsilon_{p k}}=(1-\alpha)+\alpha \exp \left[-\left(\frac{\varepsilon_{p k}}{a}\right)^{m}\right] .
$$

The derivation of (13) is obtained:

$$
\frac{d \sigma}{d \varepsilon}=(1-\alpha) E+\alpha E \exp \left[-\left(\frac{\varepsilon}{a}\right)^{m}\right]\left[1-m\left(\frac{\varepsilon}{a}\right)^{m}\right] \text {. }
$$

By substituting condition (4) into equation (17), it is obtained that

$$
\frac{d \sigma_{p k}}{d \varepsilon_{p k}}=(1-\alpha) E+\alpha E \exp \left[-\left(\frac{\varepsilon_{p k}}{a}\right)^{m}\right]\left[1-m\left(\frac{\varepsilon_{p k}}{a}\right)^{m}\right] .
$$

Because of the elastic modulus $E \neq 0$, then,

$$
(1-\alpha)+\alpha \exp \left[-\left(\frac{\varepsilon_{p k}}{a}\right)^{m}\right]\left[1-m\left(\frac{\varepsilon_{p k}}{a}\right)^{m}\right]=0 .
$$

The result is obtained from simultaneous solution equations (16) and (17):

$$
\left(\frac{\varepsilon_{p k}}{a}\right)^{m}=\frac{\left(\sigma_{p k} / E \varepsilon_{p k}\right)}{m\left[\left(\sigma_{p k} / E \varepsilon_{p k}\right)-(1-\alpha)\right]} .
$$

Make the equation $t=\left(\sigma_{p k} / E \varepsilon_{p k}\right)-(1-a)$ true; we can get that

$$
\begin{aligned}
& m=\frac{-\sigma_{p k}}{E t \varepsilon_{p k}(\ln t-\ln \alpha)}, \\
& a=\varepsilon_{p k}^{((m+1) / m)}\left[\frac{m t E}{\sigma_{p k}}\right]^{m} .
\end{aligned}
$$

\section{Laboratory Test}

4.1. Material Characteristics. CPB is mainly composed of cementitious agent, aggregate, and water. The test water is ordinary urban tap-water. The test cement is PO425 [33, 34] ordinary Portland cement produced by Jidong Heidelberg (Jingyang) Cement Co., Ltd. The test aggregate is tailings 


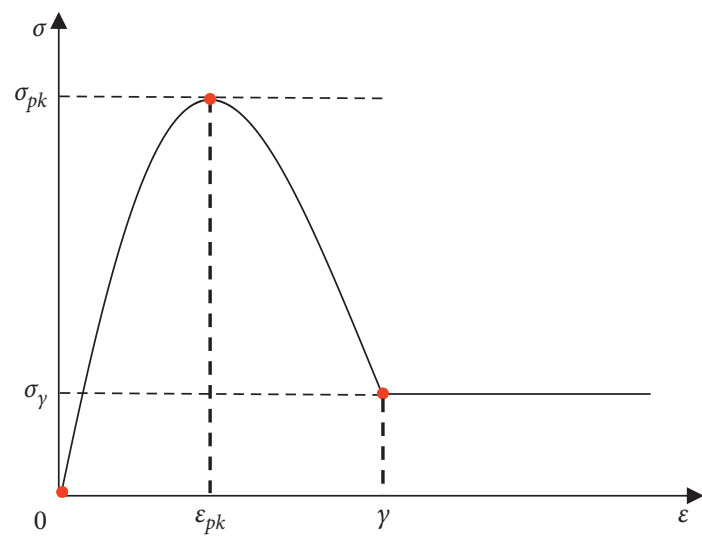

Figure 1: Stress-strain curves.

from a copper mine. The density of cement clinker is $2.87 \mathrm{~g} /$ $\mathrm{cm}^{3}$, grain size $d_{50}$ is $11 \mu \mathrm{m}$, the initial setting time is $162 \mathrm{~min}$, the final setting time is $203 \mathrm{~min}$, and the 28 -day compressive strength is $41.5 \mathrm{MPa}$. The main chemical composition of cement is $\mathrm{CaO}$ (accounting for 64.1\%), $\mathrm{SiO}_{2}$ (accounting for 19.2\%), $\mathrm{Al}_{2} \mathrm{O}_{3}$ (accounting for 4.50\%), $\mathrm{Fe}_{2} \mathrm{O}_{3}$ (accounting for $3.33 \%$ ), $\mathrm{MgO}$ (accounting for $1.82 \%$ ), and $\mathrm{S}$ (accounting for $1.06 \%$ ).

Figure 2(a) shows the particle size distribution of tailings measured by laser particle size distribution analyzer. The figure shows that $d_{10}=8.54 \mu \mathrm{m}, d_{20}=66.9 \mu \mathrm{m}$, $d_{50}=129 \mu \mathrm{m}, d_{60}=163 \mu \mathrm{m}$, the nonuniformity coefficient $C_{\mathrm{u}}=19.08$, and the curvature coefficient $C_{\mathrm{c}}=3.22$. The grading curve of tailings is smooth and continuous, the slope is gentle, the grading is good, the compactness is easy to obtain, the compressibility is low, the strength is high, and the engineering property is excellent. Figure 2(b) shows the chemical composition of tailings measured by X-ray fluorescence spectrometer (XRF). Among them, $\mathrm{CaO}$ content is less than $10 \%$, which is low calcium tailings.

4.2. Specimen Making. According to GB/T 50266-2013 "standard for test methods of engineering rock mass" [35], eight groups of cylinder specimens with cement-tailings ratios of $1: 4,1: 6,1: 8$, and $1: 10$, slurry concentration of $70 \%, 72 \%, 74 \%, 76 \%$, and $78 \%$, and curing age of 28 days under standard environment were made. The number of specimens in each group is 4 , including 3 UCS tests and 1 NMR test. The slurry composition of $\mathrm{CPB}$ is shown in Table 1, and the specific test idea and process are shown in Figure 3.

\subsection{Analysis on the Influence of Slurry Concentration and Cement-Tailings ratio}

4.3.1. Analysis of NMR Test Results. Figure 4 shows the influence of slurry concentration and cement-tailings ratio on porosity and pore size of CPB. It can be seen from Figure 4(a) that with the increase of the slurry concentration, the porosity of the CPB gradually decreases. When the slurry concentration increases from $72 \%$ to $74 \%$, the porosity obviously decreases with a larger gradient, while with the continuous increase of the slurry concentration, the porosity remains about $3 \%$. It can be seen from Figure 4(b) that with the decrease of the cement-tailings ratio, the porosity of the $\mathrm{CPB}$ gradually increases. When the cement-tailings ratio decreases from $1: 8$ to $1: 10$, the porosity increases obviously with a larger gradient, while when the cement-tailings ratio increases from $1: 8$ to $1: 4$, the porosity remains about $3 \%$.

It can be seen from Figures 4(a) and 4(b) that the proportion of large pore $(>50 \mathrm{~nm})$ gradually increases and that of small pore $(<50 \mathrm{~nm})$ gradually decreases with the increase of slurry concentration or cement-tailings ratio of CPB. The porosity of CPB body is about $3 \sim 5 \%$. From the point of view of microscopic characteristics, the slurry concentration with $74 \%$ and $76 \%$ and cement-tailings ratio with $1: 4$ and $1: 6$ are reasonable.

4.3.2. Analysis of USC Test Results. Figure 5 shows the influence of slurry concentration and cement-tailings ratio of $\mathrm{CPB}$ on elastic modulus, peak strength, and residual strength. It can be seen from Figure 5 that the elastic modulus, peak strength, and residual strength of the $\mathrm{CPB}$ increase with the increase of the slurry concentration or the cement-tailings ratio. The 28-day compressive strength can reach $8 \mathrm{MPa}$, residual strength can reach $1 \sim 2 \mathrm{MPa}$, and elastic modulus is approximately $200 \sim 2000 \mathrm{MPa}$, respectively. When the slurry concentration is $74 \%$ and $76 \%$, the mechanical properties are similar.

\section{Model Validation and Analysis}

5.1. Theoretical Model Validation. The basic mechanical parameters such as elastic modulus, peak stress, and peak load strain can be obtained from the UCS test of CPB. Combined with the model parameter equation (equations (14), (20), and (21)), the damage strengthening coefficient $a$ and damage threshold $\gamma$ of 8 groups of CPB specimens under different slurry concentrations and cement-tailings ratios can be fitted, and the corresponding Weibull statistical distribution parameters $m$ and $a$ can be calculated, as shown in Table 2. The elastic modulus of CPB is calculated by $E_{50}$ method $[18,36] . E_{50}$ refers to $50 \%$ of the maximum stress of concrete materials in the whole process from loading to destruction divided by its corresponding strain value. The residual strength is taken as the maximum curvature point in the descending section of the stress-strain curve and the average stress after the point. The damage threshold is the strain value at the same stress value as the residual strength in the theoretical curve.

In order to validate the correctness of the damage constitutive model of CPB based on the damage strengthening coefficient established in this paper, the constitutive model calculated by the theoretical model is compared with the UCS test results, and the evolution of damage variables in the whole stress-strain process is analyzed, as shown in Figure 6. 


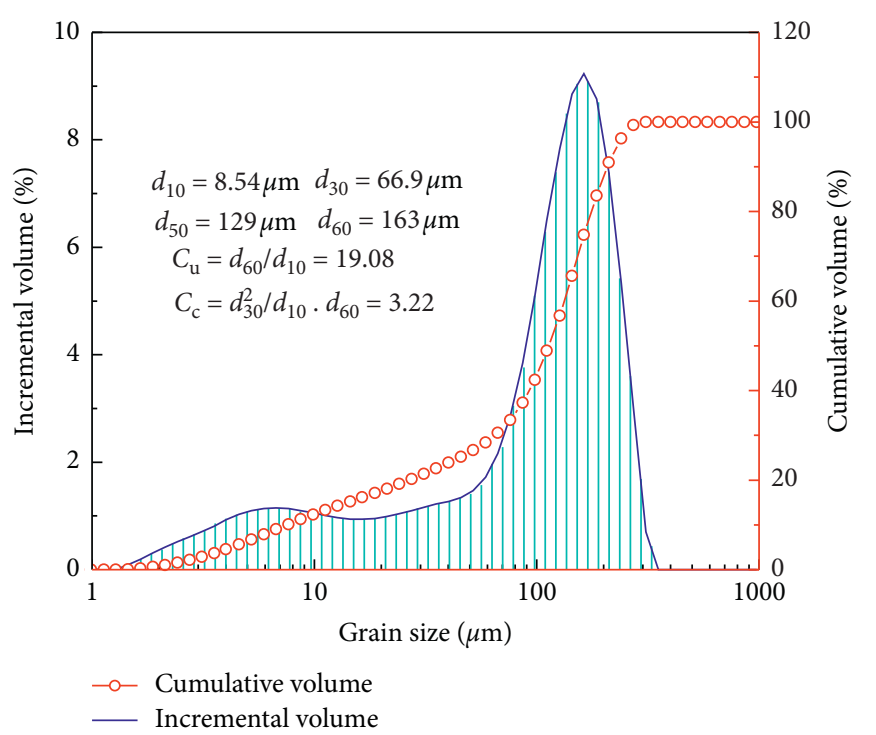

(a)

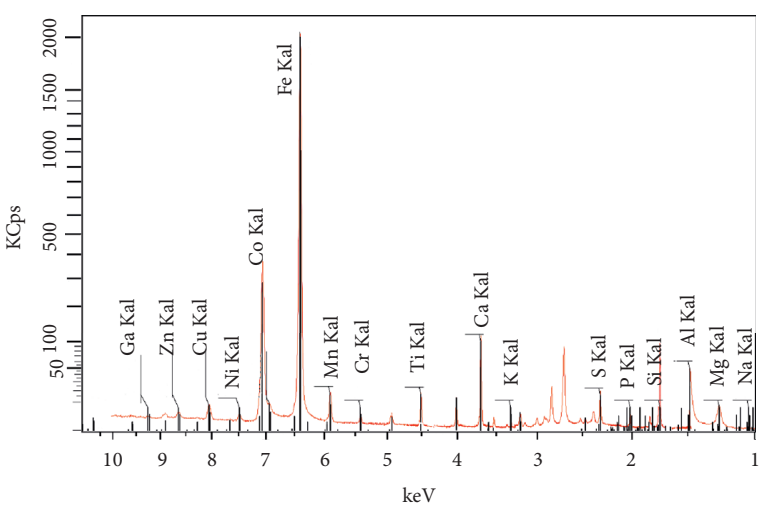

(b)

FIgURe 2: Material characteristics of tailings. (a) Particle size distribution of tailings; (b) X-ray fluorescence pattern of tailings.

TABLe 1: Composition of filling slurry.

\begin{tabular}{lccccc}
\hline Number & Cement-tailings ratio & Slurry concentration $(\%)$ & Tailings $(\mathrm{kg})$ & Cement $(\mathrm{kg})$ & Water $(\mathrm{kg})$ \\
\hline 1 & $1: 4$ & 70 & 1.08 & 0.27 & 0.58 \\
2 & $1: 4$ & 72 & 1.11 & 0.28 & 0.28 \\
3 & $1: 4$ & 74 & 1.14 & 0.29 & 0.50 \\
4 & $1: 4$ & 76 & 1.17 & 0.30 & 0.46 \\
5 & $1: 4$ & 78 & 1.20 & 0.42 \\
6 & $1: 6$ & 76 & 1.25 & 0.16 & 0.46 \\
7 & $1: 8$ & 76 & 1.30 & 0.13 & 0.46 \\
8 & $1: 10$ & 76 & 1.33 & & 0.46 \\
\hline
\end{tabular}

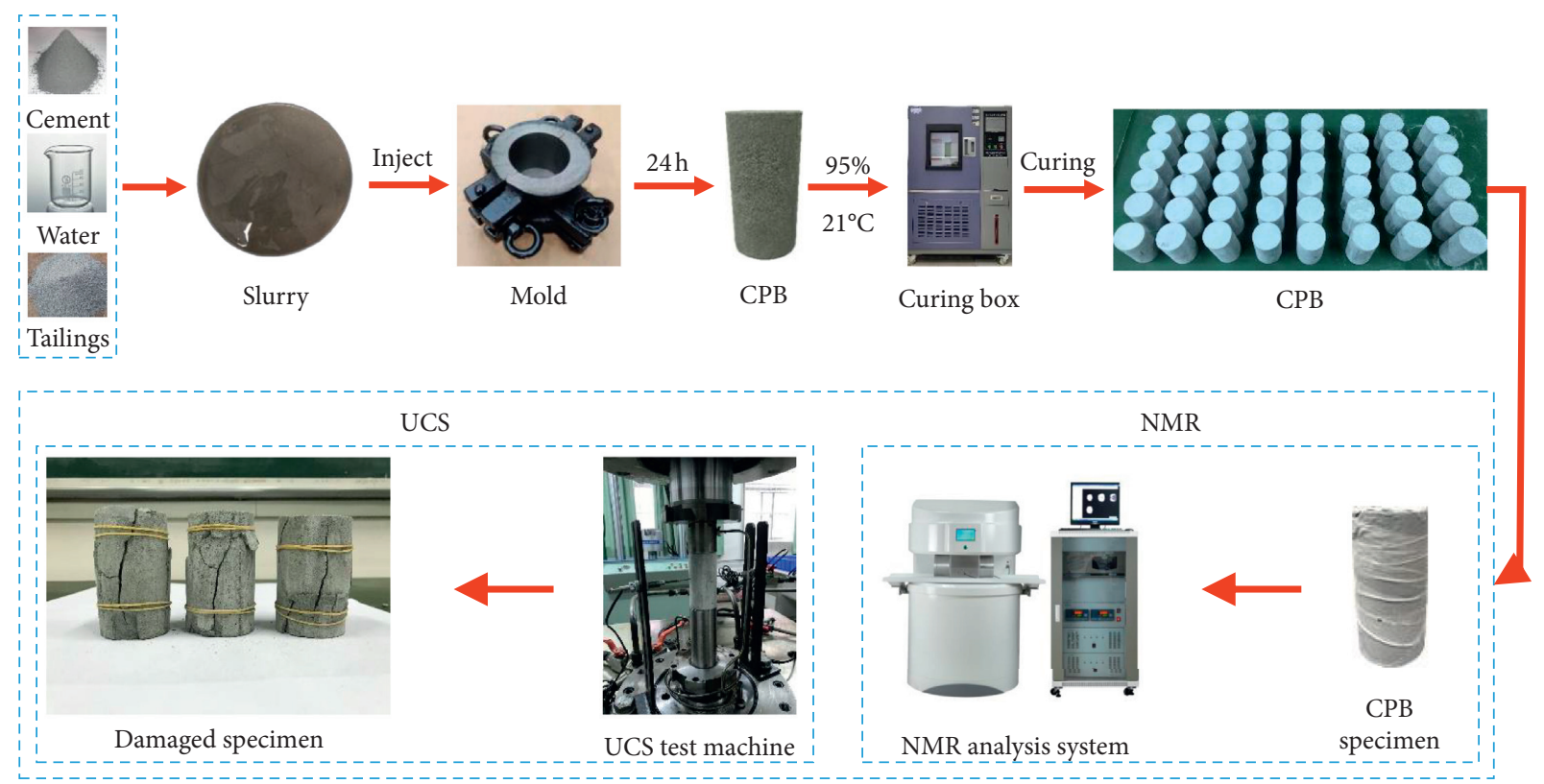

Figure 3: Experimental flow picture. 

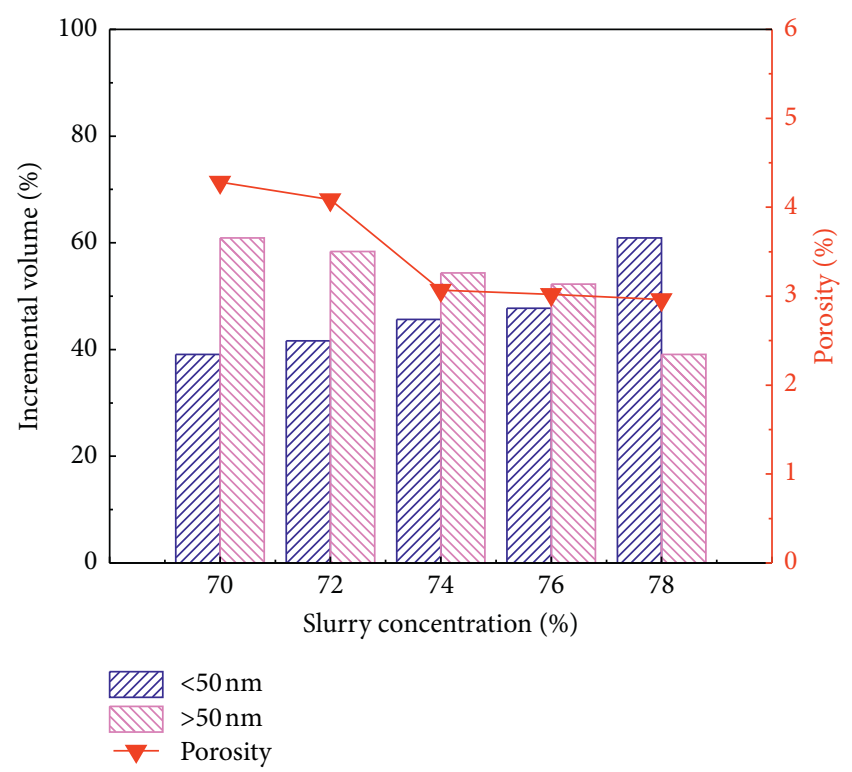

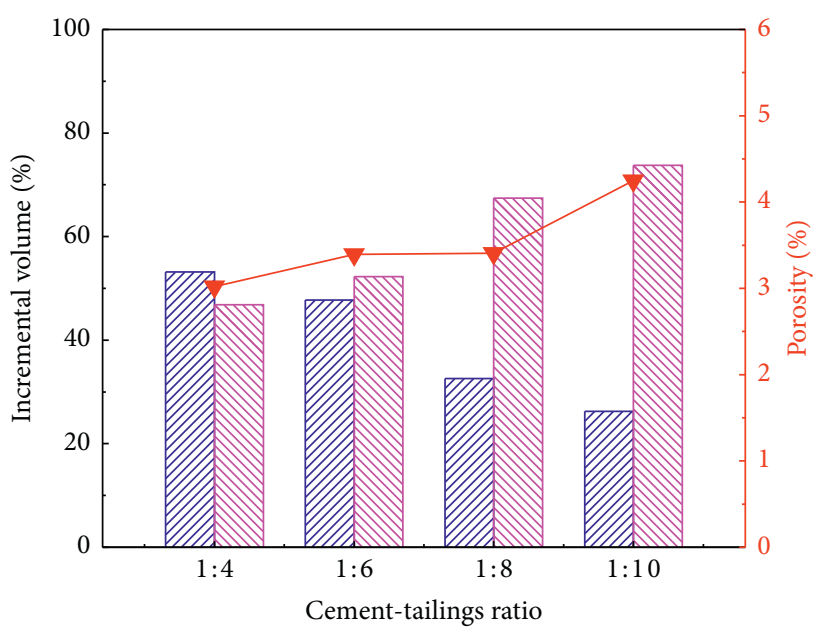

WIt $<50 \mathrm{~nm}$
MU $>50 \mathrm{~nm}$
$-\square$ Porosity

(a)

(b)

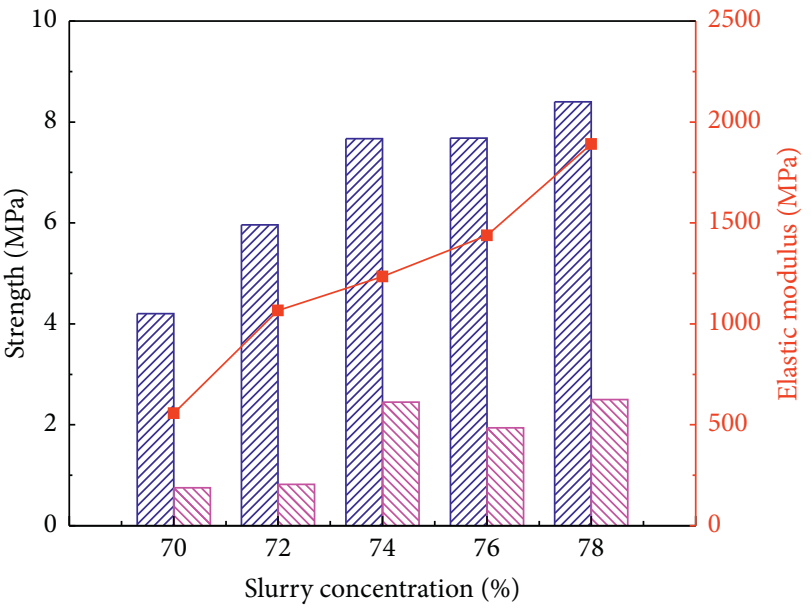

WIA Peak strength
$\mathbb{W}$ Residual strength
$--E$

(a)
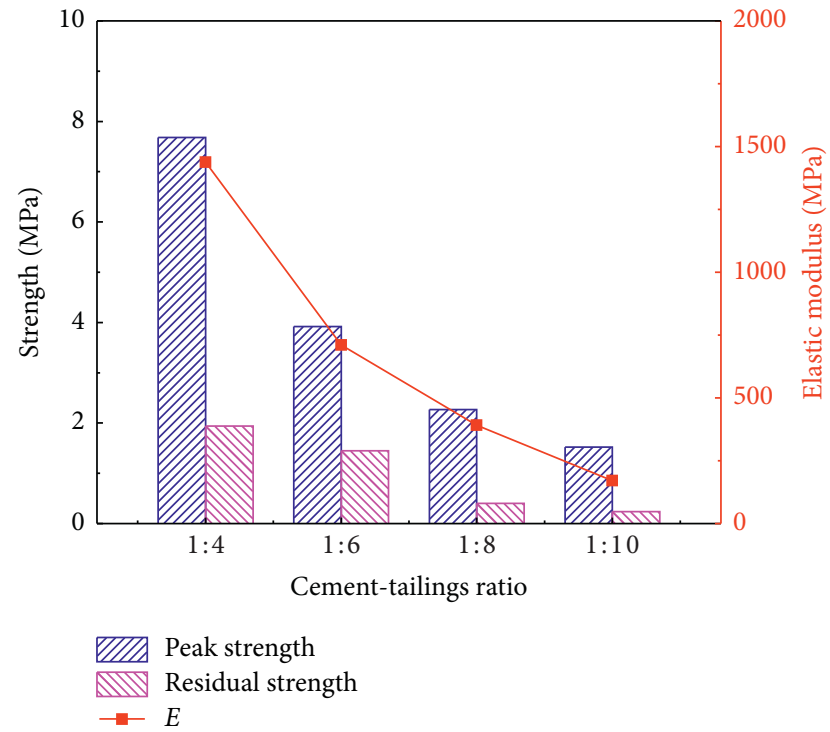

(b)

Figure 5: Basic mechanical parameters of CPB. (a) Slurry concentration effect; (b) cement-tailings ratio effect.

It can be seen from Figure 6 that the theoretical curve obtained from the damage constitutive calculation based on the damage strengthening coefficient proposed in this paper is in good agreement with the UCS test curve, which can effectively reflect the basic mechanical characteristics of the $\mathrm{CPB}$ under uniaxial compression. It can be seen from the distribution of damage variables in Figure 6 that the damage development trend of $\mathrm{CPB}$ with different cement-tailings ratios is similar, and they all approximate to the growth trend of the shape of the word "factory." With the increase of axial strain, the damage variable increases gradually. When the axial strain reaches the peak load strain, the damage increases exponentially. When the axial strain reaches the damage threshold, the damage variable tends to $90 \%$. When the damage variable is about 0.25 , the stress reaches the peak. The ratio of peak load strain to damage variable corresponding to damage threshold is about 0.25 under different cement-tailings ratios. The results show that when the damage variable reaches $1 / 4$ of the threshold damage variable, the stress-strain curve shows a downward trend, the 
TABle 2: Parameters of damage constitutive model.

\begin{tabular}{|c|c|c|c|c|c|c|c|c|}
\hline Number & Elastic modulus $(\mathrm{MPa})$ & Peak stress $(\mathrm{MPa})$ & Peak load strain (\%) & Residual strength (MPa) & $\alpha$ & $m$ & $a(\%)$ & $\gamma(\%)$ \\
\hline 1 & 557.83 & 4.20 & 0.97 & 0.75 & 1.20 & 3.83 & 1.47 & 1.61 \\
\hline 2 & 1066.64 & 5.96 & 0.73 & 0.82 & 1.16 & 3.70 & 1.09 & 1.25 \\
\hline 3 & 1234.73 & 7.67 & 0.71 & 2.45 & 1.12 & 7.78 & 0.93 & 0.96 \\
\hline 4 & 1437.79 & 7.68 & 0.69 & 1.94 & 1.06 & 3.75 & 1.01 & 1.18 \\
\hline 5 & 1890.97 & 8.40 & 0.56 & 2.50 & 1.02 & 4.23 & 0.79 & 0.92 \\
\hline 6 & 710.14 & 3.92 & 0.71 & 1.51 & 1.18 & 4.59 & 1.04 & 1.06 \\
\hline 7 & 391.09 & 2.27 & 0.80 & 0.40 & 1.22 & 2.95 & 1.28 & 1.43 \\
\hline 8 & 170.31 & 1.52 & 0.85 & 0.22 & 1.24 & 3.17 & 1.48 & 1.65 \\
\hline
\end{tabular}

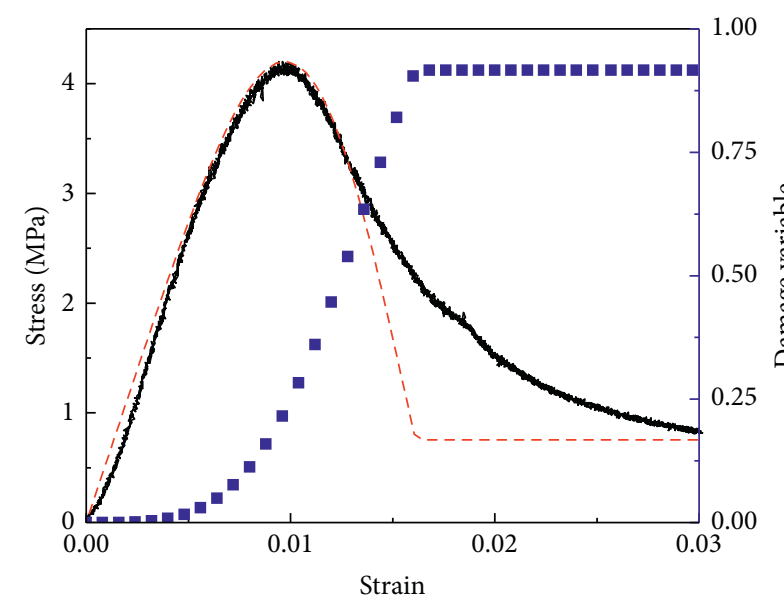

- Text curve

- - - Theoretical curve

- Damage variable

(a)

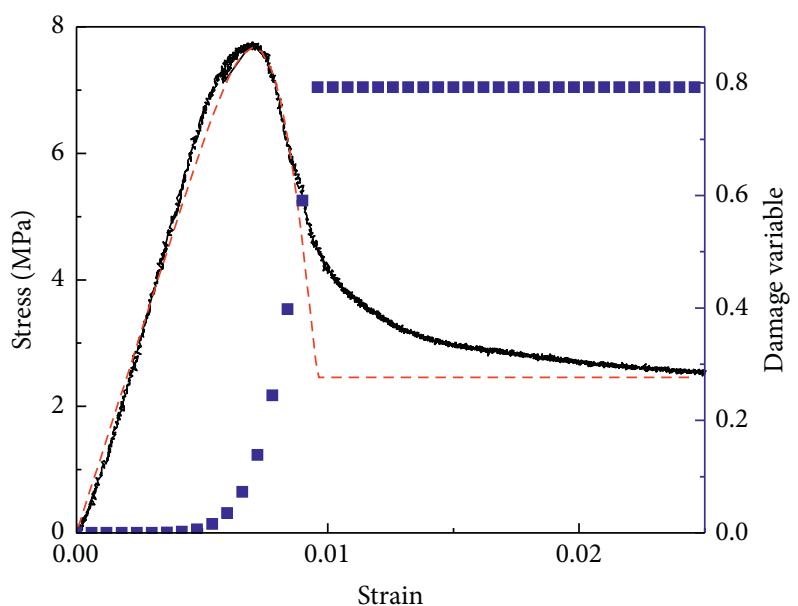

Text curve

- - Theoretical curve

- Damage variable

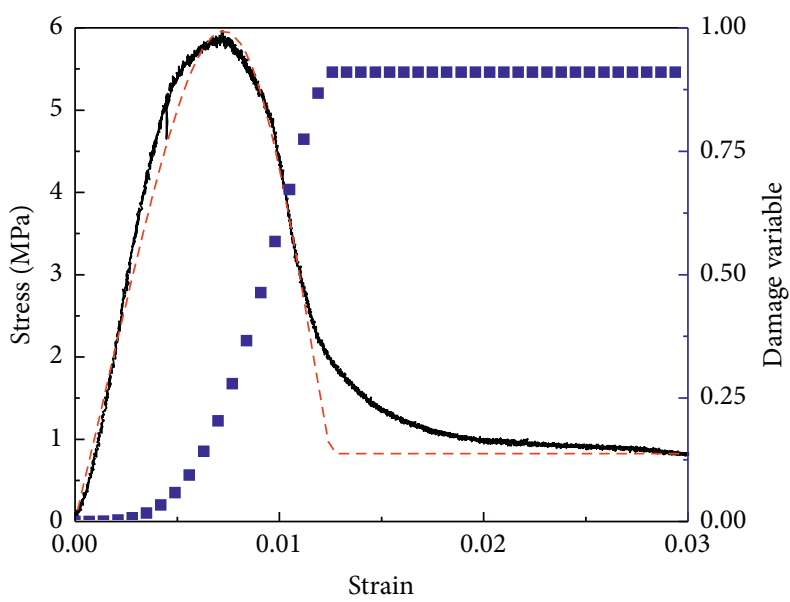

- Text curve

- _ - Theoretical curve

- Damage variable

(b)

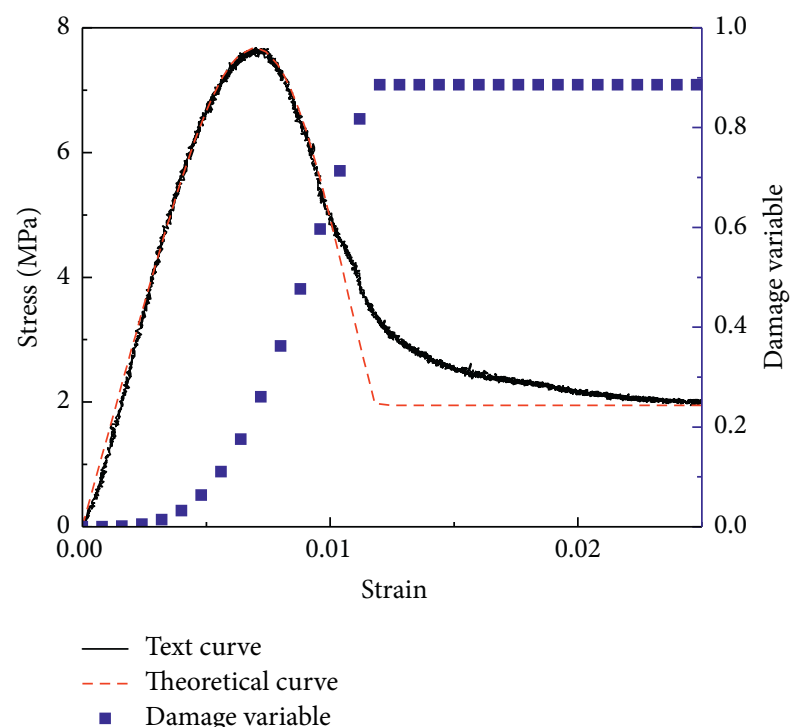

(d)

FIgURE 6: Continued. 


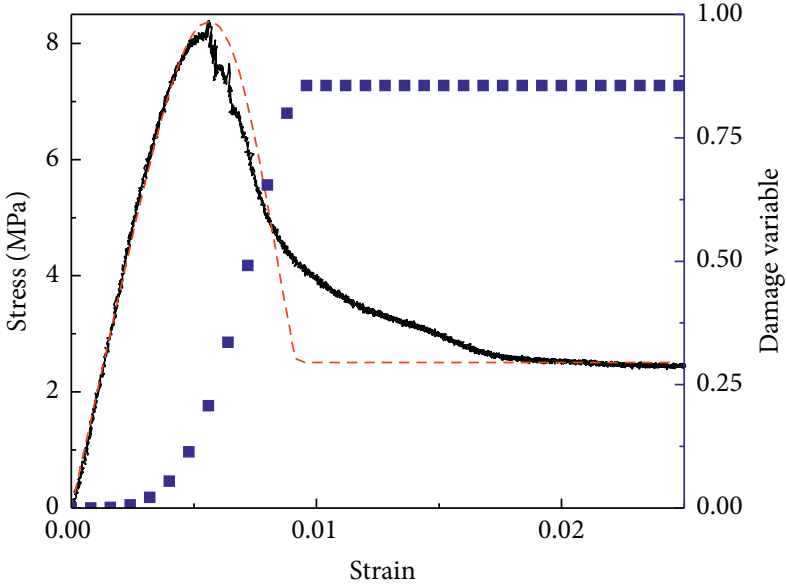

- Text curve

- - - Theoretical curve

- Damage variable

(e)

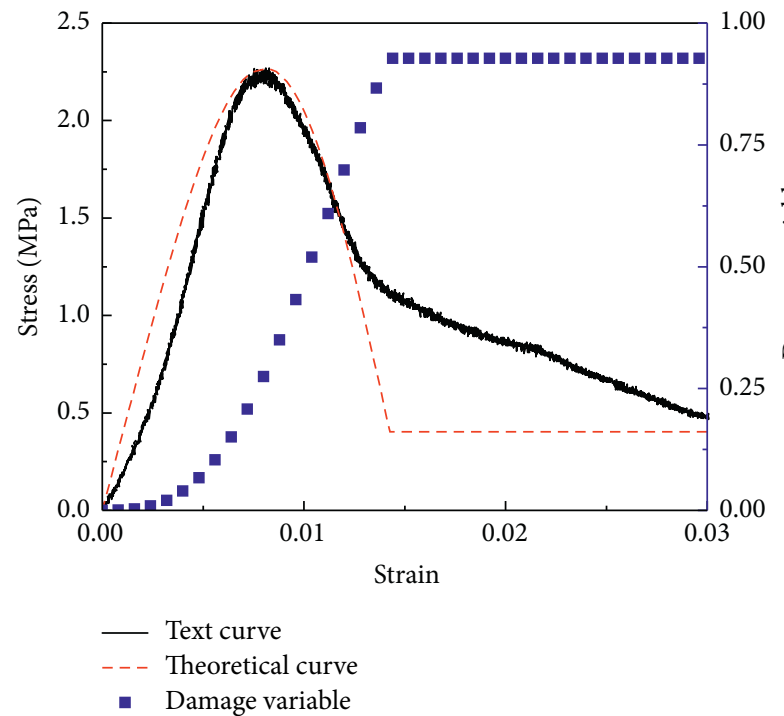

(g)

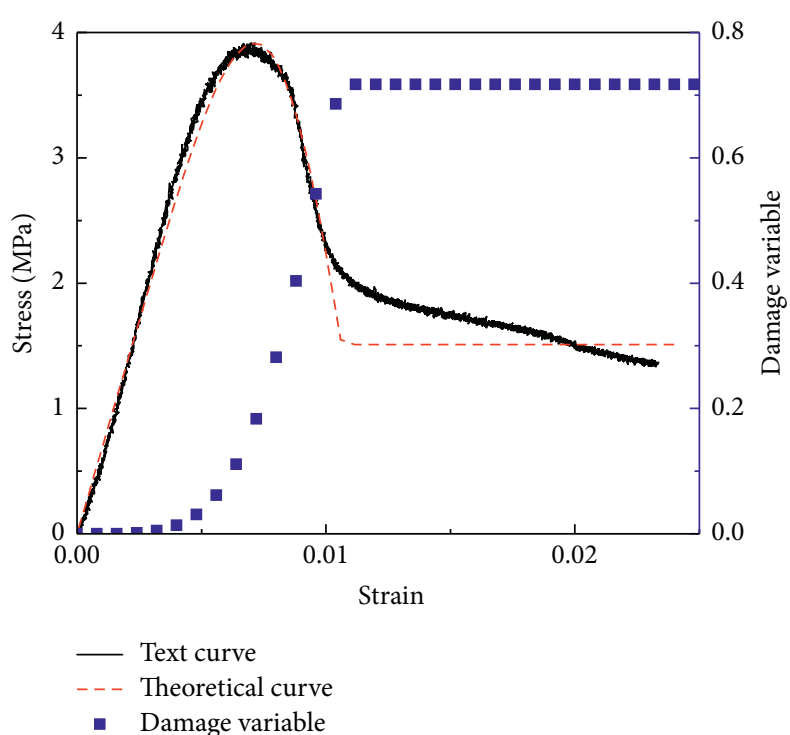

(f)

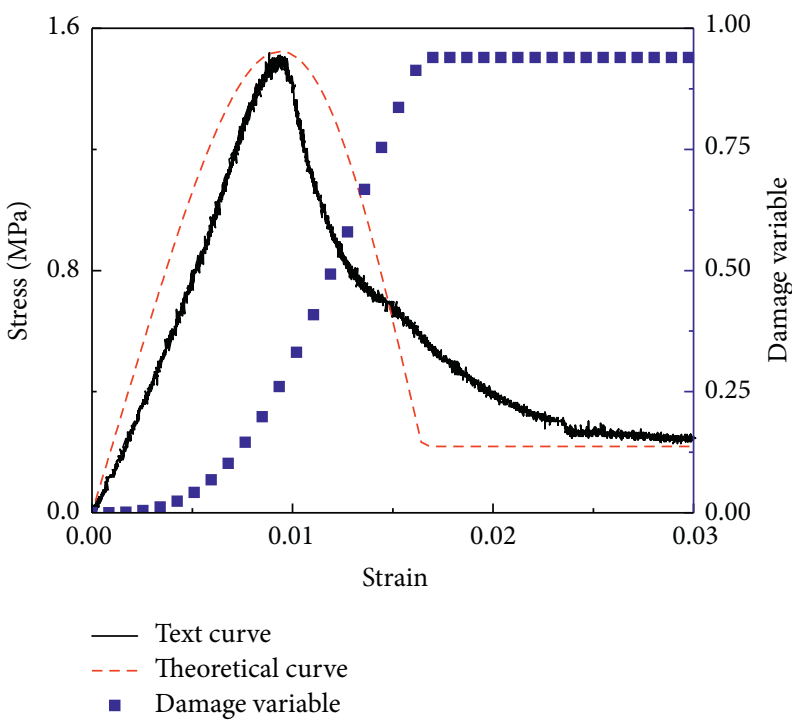

(h)

FIgURE 6: Damage variable and comparison of damage constitutive models. (a) Cement-tailings ratio is $1: 4$ and slurry concentration is $70 \%$; (b) cement-tailings ratio is $1: 4$ and slurry concentration is $72 \%$; (c) cement-tailings ratio is $1: 4$ and slurry concentration is $74 \%$; (d) cementtailings ratio is $1: 4$ and slurry concentration is $76 \%$; (e) cement-tailings ratio is $1: 4$ and slurry concentration is $78 \%$; (f) cement-tailings ratio is $1: 6$ and slurry concentration is $76 \%$; $(\mathrm{g})$ cement-tailings ratio is $1: 8$ and slurry concentration is $76 \%$; $(\mathrm{h})$ cement-tailings ratio is $1: 10$ and slurry concentration is $78 \%$.

damage growth rate is accelerated, and the CPB is easy to be destroyed.

5.2. Analysis of Damage Strengthening Coefficient. According to the analysis of the NMR test results, the main pore type of $\mathrm{CPB}$ is capillary pore, and the pore size range is $2.5 \sim 10^{4} \mathrm{~nm}$. When analyzing the influence of pore size on material strength, the pore size should be classified and the influence coefficient should be calculated in different pore size areas. In this paper, the pore size is taken as the average value, and then the expression of damage strengthening coefficient and the relevant parameters in equation (2) are taken with reference to [31], and then equation (2) is expressed as

$$
\alpha=1.365 d^{0.156}(1+P)^{k}+c
$$

MATLAB is used to fit equation (22) with two parameters, and the fitting equation of damage strengthening coefficient is obtained in equation (23); the results are shown in Figure 7.

$$
\alpha=1.365 d^{0.156}(1+P)^{0.1558}-0.7583 .
$$




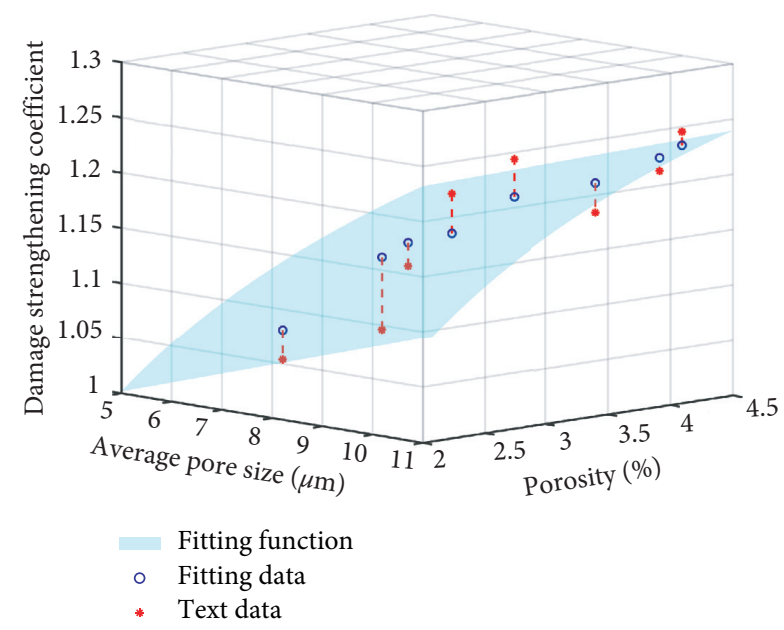

FIGURE 7: Fitting effect drawing of damage strengthening factor.

\section{Conclusion}

In this paper, a damage constitutive model based on the damage strengthening coefficient is proposed, considering the influence of microcosmic pore characteristics of CPB. The validity of the theoretical model is verified by UCS test and NMR test. The exponential expression of damage strengthening coefficient is given, which can effectively describe the stress-strain relationship and damage evolution process of $\mathrm{CPB}$ under uniaxial compression. The main conclusions are as follows:

(1) Under uniaxial compression, when the damage variable is about 0.25 , the stress reaches the peak value. The ratio of peak load strain to damage variable corresponding to damage threshold is about 0.25 .

(2) The 28-day compressive strength of CPB can reach $8 \mathrm{MPa}$, the residual strength is about $1 \sim 2 \mathrm{MPa}$, the elastic modulus is about 200 2000 MPa, the porosity is about $3 \sim 5 \%$, the damage strengthening coefficient is about $1 \sim 1.2$, and the damage threshold is about $1 \sim 1.5 \%$.

(3) From the perspective of microscopic characteristics, the CPB with slurry concentration of $74 \%$ and $76 \%$ and cement-tailings ratio of $1: 4$ and $1: 6$ is more reasonable, and the relevant mechanical parameters are more stable.

\section{Data Availability}

Data are available from the corresponding author upon request.

\section{Conflicts of Interest}

Liu Lang, Cheng Kangli, Tu Bingbing, Zhang Bo, and Qiu Huafu declare that they have no conflicts of interest.

\section{Acknowledgments}

Projects (52074212 and 51874229) were supported by the National Science Foundation of China; project (2019JQ-354) was supported by the Science and Technology Department of Shaanxi Province of China.

\section{References}

[1] L. Dong, X. Tong, X. Li, J. Zhou, S. Wang, and B. Liu, "Some developments and new insights of environmental problems and deep mining strategy for cleaner production in mines," Journal of Cleaner Production, vol. 210, no. 2, pp. 1562-1578, 2019.

[2] L. Dong, W. Shu, X. Li, and J. Zhang, "Quantitative evaluation and case studies of cleaner mining with multiple indexes considering uncertainty factors for phosphorus mines," Journal of Cleaner Production, vol. 183, no. 5, pp. 319-334, 2018.

[3] K. Zhao, S. T. Zhu, K. P. Zhou et al., "Research on mechanical properties and damage law of tantalum-niobium ore cemented tailings backfill," Journal of Mining \& Safety Engineering, vol. 3, pp. 413-419, 2019.

[4] G. Huang, S. J. Cai, Y. D. Zhang, and D. Wu, "Experimental and modeling study on the strength of tailings backfill in underground mine," Applied Mechanics \& Materials, vol. 522524, pp. 1390-1393, 2014.

[5] Z. H. Wu, H. G. Ji, H. Q. Jiang, Z.-J. Qi, and Y. P. Kou, "Study of mechanical properties of frozen saline cemented tailings backfill," Rock and Soil Mechanics, vol. 41, no. 6, pp. 1874-1880, 2020.

[6] X. Zhang, M. Zhao, L. Liu et al., "Numerical simulation on heat storage performance of backfill body based on tube-intube heat exchanger," Construction and Building Materials, vol. 265, no. 9, p. 120340, 2020.

[7] R. L. Hu, Z. Q. Yue, L. C. Wang, and S. J. Wang, "Review on current status and challenging issues of land subsidence in China," Engineering Geology, vol. 76, no. 1-2, pp. 65-77, 2004.

[8] R. Rankine, M. Pacheco, and N. Sivakugan, "Underground mining with backfills," Soils and Rocks, vol. 30, no. 2, pp. 93-101, 2007.

[9] B. Ercikdi, A. Kesimal, F. Cihangir, H. Deveci, and İ. Alp, "Cemented paste backfill of sulphide-rich tailings: Importance of binder type and dosage," Cement and Concrete Composites, vol. 31, no. 4, pp. 268-274, 2009.

[10] M. Fall, M. Benzaazoua, and E. G. Saa, "Mix proportioning of underground cemented tailings backfill," Tunnelling and Underground Space Technology, vol. 23, no. 1, pp. 80-90, 2008.

[11] Y. Q. Hou, S. H. Yin, Y. Cao et al., "Analysis of damage characteristics and energy dissipation of cemented tailings backfill with different curing ages under uniaxial compression," Journal of Central South University (Science and Technology), vol. 7, pp. 1955-1965, 2020.

[12] K. Zhao, W. J. Xie, P. Zeng et al., "Experimental study on damage characteristics of cemented tailings backfill failure process with different concentration," Journal of Applied Acoustics, vol. 7, pp. 543-549, 2020.

[13] X. F. Yi, C. K. Liu, and Y. Wang, "Experimental study on the meso-mechanical properties of cemented waste rock-tailings backfill (CWRB) using in-situ X-ray CT scanning," Rock and Soil Mechanics, vol. 10, pp. 1-8, 2020.

[14] Z. X. Liu, Q. L. Liu, and W. G. Dang, "On softening-hardening intrinsically constitutive model for damage of tailingscemented filling body," Journal of Shandong University of Science and Technology (Natural Science), vol. 2, pp. 36-41, 2012. 
[15] S. G. Zhao, D. L. Su, W. R. Wu et al., "Study on damage model of backfill based," China Mining Magazing, vol. 2, pp. 106$111,2017$.

[16] J. Wang, W. D. Song, Y. Y. Tan et al., "Damage constitutive model and strength criterion of horizontal stratified cemented backfill," Rock and Soil Mechanics, vol. 5, pp. 1731-1739, 2019.

[17] L. Cui and M. Fall, "An evolutive elasto-plastic model for cemented paste backfill," Computers and Geotechnics, vol. 71, pp. 19-29, 2016.

[18] Y. Wang, A. X. Wu, H. J. Wang et al., "Damage constitutive model of cemented tailing paste under initial temperature effect," Chinese Journal of Engineering, vol. 39, no. 1, pp. 31-38, 2017.

[19] L. Cui and M. Fall, "A coupled thermo-hydro-mechanicalchemical model for underground cemented tailings backfill," Tunnelling and Underground Space Technology, vol. 50, pp. 396-414, 2015.

[20] Z. X. Liu, X. B. Li, T. G. Dai et al., "On damage model of cemented tailings backfill and its match with rock mass," Rock and Soil Mechanics, vol. 9, pp. 1442-1446, 2006.

[21] F. H. Wittmann, P. E. Roelfstra, and H. Sadouki, "Simulation and analysis of composite structures," Materials Science and Engineering, vol. 68, no. 2, pp. 239-248, 1985.

[22] X. L. Du and L. Jin, "Applications of meso-scale analysis methods on the studyof the physical/mechanical properties of concrete," Shuili Xuebao, vol. 3, pp. 355-371, 2016.

[23] B. Pichler, S. Scheiner, and C. Hellmich, "From micron-sized needle-shaped hydrates to meter-sized shotcrete tunnel shells: micromechanical upscaling of stiffness and strength of hydrating shotcrete," Acta Geotechnica, vol. 3, no. 4, pp. 273-294, 2008.

[24] B. Pichler, C. Hellmich, and J. Eberhardsteiner, "Spherical and acicular representation of hydrates in a micromechanical model for cement paste: prediction of early-age elasticity and strength," Acta Mechanica, vol. 203, no. 3-4, pp. 137-162, 2009.

[25] X. L. Du and L. Jin, "Research on effective mechanical proerties of concrete composite material with pores," Engineering Mechanics, vol. 6, pp. 70-77, 2012.

[26] W. B. Xu, W. D. Pang, and M. L. Ding, "Experiment on evolution of microstructures and long-term strength model of cemented backfill mass," Journal of Central South University (Science and Technology), vol. 46, no. 6, pp. 2333-2341, 2015.

[27] D. S. Shi and A. Wang, "Effect of slag fine aggregate concrete pore structure on compressive strength," Concrete, vol. 3, pp. 80-83, 2016.

[28] C. Lian, Y. Zhuge, and S. Beecham, "The relationship between porosity and strength for porous concrete," Construction and Building Materials, vol. 25, no. 11, pp. 4294-4298, 2011.

[29] Erniati, M. W. Tjaronge, Zulharnah, and U. R. Irfan, "Porosity, pore size and compressive strength of self compacting concrete using sea water," Procedia Engineering, vol. 125, pp. 832-837, 2015.

[30] S. Jin, J. Zhang, and S. Han, "Fractal analysis of relation between strength and pore structure of hardened mortar," Construction and Building Materials, vol. 135, pp. 1-7, 2017.

[31] D. Li, Z. Li, C. Lv, G. Zhang, and Y. Yin, "A predictive model of the effective tensile and compressive strengths of concrete considering porosity and pore size," Construction and Building Materials, vol. 170, pp. 520-526, 2018.

[32] J. Lemaitre, "How to use damage mechanics," Nuclear Engineering and Design, vol. 80, no. 2, pp. 233-245, 1984.

[33] L. Liu, J. Xin, C. Huan, C. Qi, W. Zhou, and K.-I. Song, "Pore and strength characteristics of cemented paste backfill using sulphide tailings: effect of sulphur content," Construction and Building Materials, vol. 237, pp. 117452-117512, 2020.

[34] L. Liu, J. Xin, C. C. Qi, H. Jia, and K.-I. Song, "Experimental investigation of mechanical, hydration, microstructure and electrical properties of cemented paste backfill," Construction and Building Materials, vol. 263, pp. 1-12, 2020.

[35] MOHURD, GB/T. 50266-2013, Standard for test methods of engineering rock mass, MOHURD, vol. 1, p. 28, China, 2013.

[36] Y. Wang, Initial Temperature-Dependence of Multi-Field Property Correlation and Mechanics Behaviors for Cemented Paste Backfill, University of Science and Technology Beijing, Beijing, China, 2017. 